\title{
CORRELATION OF MICROALBUMINURIA WITH AGE, DURATION, GLYCATED HEMOGLOBIN, BLOOD SUGAR LEVELS, BLOOD PRESSURE AND RENAL PARAMETERS OF TYPE 2 DIABETES PATIENTS
}

\author{
GEETHA P*, SHANMUGASUNDARAM P \\ Department of Pharmacy Practice, Faculty of Pharmacy, School of Pharmaceutical Sciences (VISTAS), Vels University, Chennai, Tamil Nadu,
} India. Email: Igeethapharma@gmail.com

Received: 28 June 2017, Revised and Accepted: 31 July 2017

\section{ABSTRACT}

Objectives: Microalbuminuria is the strongest predictor of diabetic nephropathy, which is the main cause of morbidity and mortality. The aim of the study is to determine the prevalence of microalbuminuria in Type 2 diabetes patients and to evaluate the relation between the microalbuminuria and age, duration, glycated hemoglobin (HbA1c), blood sugar levels, blood pressure (BP), and renal parameters of Type 2 diabetes patients.

Methods: The prospective study includes 115 patients with Type 2 diabetes, visiting in outpatient diabetes hospital, Chennai. The case reports of the patients diagnosed with blood sugar, HbA1c level BP and renal parameters of Type 2 diabetes patients were recorded and compared with microalbuminuria. Statistical analysis was carried out using student t-test and Pearson correlation.

Results: The study revealed that the prevalence of microalbuminuria in this study was $27.82 \%$. Incidence of microalbuminria increases with age, duration of diabetes, blood sugar levels, and hypertension. There is no association of body mass index and sex on the prevalence of microalbuminuria in Type 2 diabetes mellitus. Creatinine clearance has shown a weak negative correlation with microalbuminuria in our study.

Conclusion: The present study showed that there is a weak positive correlation of microalbuminuria with blood sugar levels, duration and systolic BP. There is a weak negative correlation of creatinine shows that impairment in the kidney function.

Keywords: Microalbuminuria, Glycated hemoglobin, Correlation.

(C) 2017 The Authors. Published by Innovare Academic Sciences Pvt Ltd. This is an open access article under the CC BY license (http://creativecommons. org/licenses/by/4. 0/) DOI: http://dx.doi.org/10.22159/ajpcr.2017.v10i11.21015

\section{INTRODUCTION}

Diabetes mellitus (DM) is a group of metabolic diseases characterized by hyperglycemia resulting from defects in insulin secretion, insulin action, or both. The chronic hyperglycemia of diabetes is associated with long-term damage, dysfunction and failure of various organs, especially the eyes, kidneys, heart, and blood vessels [1]. Diabetic nephropathy is the leading cause of end-stage renal failure in patients with Type $2 \mathrm{DM}$, and its prevalence is increasing annually worldwide. Compared to 20 years ago, the incidence of diabetic complications without diabetic nephropathy has decreased; however, is still the main complication in diabetes [2]. Microalbuminuria is defined as levels of albumin ranging from 30 to $300 \mathrm{mg}$ in a 24-hrs urine collection [3]. Microalbuminuria was the strongest predictor of cardiovascular events in a high-risk population with underlying atherosclerosis. It was found to be stronger than other risk factors such as coronary artery disease and diabetes [4]. Microalbuminuria does not directly cause cardiovascular events; it serves as a marker for identifying those who may be at increased risk. Microalbuminuria is caused by glomerular capillary injury and so may be a marker for diffuse endothelial dysfunction [5]. There is a positive link between high blood pressure (BP) and microalbuminuria. High BP may cause microalbuminuria by increasing glomerular filtration pressure and subsequent renal damage [6]. A study from Iran documented the linear relationship of the degree of microalbuminuria with BP, and duration of diabetes [7]. This study was aimed to determine the prevalence of microalbuminuria in Type $2 \mathrm{DM}$ and to evaluate the relation between microalbuminuria and age, sex, duration, glycated hemoglobin (HbA1c), fasting blood sugar (FBS), post-prandial blood sugar (PPBS), BP, body mass index (BMI), and creatinine clearance.

\section{METHODS}

The study group comprised of 115 Type 2 diabetes patients visited as outpatients of Aruna diabetes center, Choolaimedu, Chennai. The prospective study was performed from July to October 2016. This study was approved by the Institutional Ethics Committee (Ref: IEC/ PHD/2015/2016/01), Vels University, Chennai and written informed consent was taken from all the patients. A data entry form was designed including demographic data such as age, sex, height and weight, duration of diabetes, family history, and comorbidities were recorded for each patient. These patients were diagnosed as having Type $2 \mathrm{DM}$ on the basis of $200 \mathrm{mg} / \mathrm{dl}(11.1 \mathrm{mmol} / \mathrm{L})$ or higher together with classical features of DM such as polyuria, polydipsia, polyphagia, and weight loss or a FBS levels of $>126 \mathrm{mg} / \mathrm{dl}(7.0 \mathrm{mmol} / \mathrm{L})$ or glycated HbA1c levels of $>6.5 \%$ or higher, patients with thyroid dysfunction, hypertensive patients were included in the study. We were excluded the patients with Type $1 \mathrm{DM}$, pregnant women, patients diagnosed of end-stage renal failure and patients not willing to participate in this study.

The selected patients were studied in detail with history and physical examination. The BP was recorded using a sphygmomanometer. Patients were categorized as hypertensive patients if the systolic BP $>130 \mathrm{mmHg}$ and/or diastolic BP was $>85 \mathrm{mmHg}$ [8]. BMI was calculated from the height and weight measurements of the patients.

A blood sample was taken from the patient after overnight fasting of 12 hrs to measure FBS, HbA1c, serum cholesterol, serum triglyceride levels, and serum creatinine. Urine samples were collected early in the morning after overnight fasting. The first morning urine sample was 
Table 1: Baseline characteristics of the patients

\begin{tabular}{|c|c|c|c|c|}
\hline Variable & All patients $(n=115)$ & $\begin{array}{l}\text { Microalbuminuric } \\
\text { patients }(n=32)\end{array}$ & $\begin{array}{l}\text { Normoalbuminuric } \\
\text { patients }(n=83)\end{array}$ & $p$ value \\
\hline $\operatorname{Sex}(M / F)$ & $59 / 56$ & $16 / 16$ & $40 / 43$ & \\
\hline Mean age (years) & $54.74 \pm 12.43$ & $57.13 \pm 12.04$ & $53.82 \pm 12.53$ & 0.20 \\
\hline BMI $\left(\mathrm{kg} / \mathrm{m}^{2}\right)$ & $26.57 \pm 5.04$ & $27.30 \pm 5.30$ & $26.84 \pm 4.98$ & 0.66 \\
\hline FBS (mg/dl) & $143.61 \pm 48.95$ & $156.16 \pm 59.86$ & $134.92 \pm 41.24$ & $<0.05$ \\
\hline PPBS (mg/dl) & $198.18 \pm 61.20$ & $226.5 \pm 65.66$ & $187.27 \pm 56.07$ & $<0.05$ \\
\hline HbA1c $(\%)$ & $8.80 \pm 5.86$ & $9.25 \pm 2.72$ & $8.63 \pm 6.70$ & 0.61 \\
\hline Serum creatinine (mg/dl) & $0.96 \pm 0.28$ & $1.13 \pm 0.38$ & $0.89 \pm 0.19$ & $<0.001$ \\
\hline Creatinine clearance (ml/minute) & $86.26 \pm 27.02$ & $76.47 \pm 35.29$ & $87.27 \pm 22.62$ & 0.054 \\
\hline Duration of diabetes & $10.98 \pm 7.28$ & $12.59 \pm 8.25$ & $10.36 \pm 6.81$ & 0.14 \\
\hline Systolic BP (mmHg) & $135.05 \pm 17.52$ & $144.09 \pm 20.30$ & $131.56 \pm 16.06$ & $<0.0001$ \\
\hline Diastolic BP (mmHg) & $80.21 \pm 11.05$ & $81.03 \pm 13.57$ & $79.90 \pm 9.99$ & 0.47 \\
\hline
\end{tabular}

All the values expressed as mean \pm SD, Students t-test, BMI: Body mass index, FBS: Fasting blood sugar, PPBS: Post prandial blood sugar, BP: Blood pressure, SD: Standard deviation, HbA1c: Glycated hemoglobin

assessed to check the presence of urinary tract infection and hematuria, in this conditions urine for microalbumin levels increased. Less than $30 \mathrm{mg}$ /day was considered as normal, 30-300 mg/day may indicate as microalbuminuria (early kidney disease).

Data analysis was done using the student's t-test to evaluate the significance of microalbuninuric and normoalbuminuric patients. A Pearson correlation test used to analyze the correlation of microalbuminuria with independent variables such as age, duration, HbA1c, FBS, PPBS, renal parameter, and BP. $\mathrm{p}<0.05$ was considered as statistically significant.

\section{RESULTS}

Data collected were analyzed by the student's t-test. The Pearson correlation test was used to analyze the correlation of microalbuminuria with independent variables such as age, BMI, FBS, postprandial blood sugar, $\mathrm{HbA}_{1} \mathrm{c}$, serum creatinine, systolic and diastolic BP, and creatinine clearance. $p<0.05$ were regarded as statistically significant. A total of 115 patients, 59 males and 56 females, were included in the study. The overall prevalence of microalbuminuria in the present study was $27.82 \%$. Among the patients with microalbuminuria, $16(50 \%)$ were males, and $16(50 \%)$ were females. Baseline characteristics of the patients are shown in Table 1. Age of the patient at diagnosis ranged between 18 and 86 years. Mean age at onset of DM was $54.74 \pm$ 12.43 and in microalbuminuric patients was $57.13 \pm 12.04$ and in normoalbuminuric patients was $53.82 \pm 12.53$. The difference between the two groups was not statistically significant. There was statistically significant difference in FBS, PPBS, and serum creatinine of albuminuric and normoalbuminuric patients shown in Table 1. The mean BMI of microalbuminuric patients was $27.30 \pm 5.30$ and in normoalbuminuric patients was $26.84 \pm 4.98$. The difference between the two groups was not statistically significant. The mean $\mathrm{HbA}_{1} \mathrm{c}$ of microalbuminuric patients was $9.25 \pm 2.72$ and in normoalbuminuric patients was $8.63 \pm 6.70$. The difference between the two groups was not statistically significant (Table 1 ). The Pearson correlation did not show any significance for microalbuminuria and $\mathrm{HbA}_{1} \mathrm{c}(\mathrm{r}=0.06$, $\mathrm{p}>0.05$ ) are shown in Table 2. Creatinine clearance did not show any significant between the two groups, but in gender-wise distribution shows statistically significant difference are shown in Table 3 . The mean duration of Type $2 \mathrm{DM}$ was found to be $10.98 \pm 7.28$, there is no significant difference between the two groups in both baseline characteristics and in the Pearson correlation. The maximum number of patients (30) had the duration of 11-15 years. Among these, eight patients had microalbuminuria. Twenty-nine patients had the duration of diabetes between 6 and 10 years; among them, also eight patients had microalbuminuria. Twenty-eight patients had the duration of 1-5 years, among them seven had microalbuminuria. 13 patients had the duration of diabetes $>20$ years, among them seven had microalbuminnuria (Table 4). The mean FBS was 143.61
Table 2: Correlation of microalbuminuria with independent variables

\begin{tabular}{lll}
\hline Variable & $\begin{array}{l}\text { Mean } \pm \text { SD } \\
(\mathbf{n}=115)\end{array}$ & $\begin{array}{l}\text { Correlation } \\
\text { coefficient (r) }\end{array}$ \\
\hline Mean age (years) & $54.74 \pm 12.43$ & 0.206 \\
BMI (kg/m $\left.{ }^{2}\right)$ & $26.57 \pm 5.04$ & -0.027 \\
FBS (mg/dl) & $143.61 \pm 48.95$ & 0.323 \\
PPBS (mg/dl) & $198.18 \pm 61.20$ & 0.31 \\
HbA1c (\%) & $8.80 \pm 5.86$ & 0.066 \\
Serum creatinine (mg/dl) & $0.96 \pm 0.28$ & 0.451 \\
Creatinine clearance (ml/minute) & $86.26 \pm 27.02$ & -0.289 \\
Duration of diabetes & $10.98 \pm 7.28$ & 0.176 \\
Systolic BP (mmHg) & $135.05 \pm 17.52$ & 0.438 \\
Diastolic BP (mmHg) & $80.21 \pm 11.05$ & 0.029 \\
\hline
\end{tabular}

All the values expressed as mean $\pm S D$; Pearson correlation coefficient, BMI: Body mass index, FBS: Fasting blood sugar, PPBS: Post prandial blood sugar, BP: Blood pressure, HbA1c: Glycated hemoglobin, SD: Standard deviation

Table 3: Gender-wise comparison of the patients

\begin{tabular}{llll}
\hline Variables & Male & Female & p value \\
\hline Mean age (years) & $54.78 \pm 12.91$ & $57.40 \pm 12.03$ & 0.26 \\
BMI $\left(\mathrm{kg} / \mathrm{m}^{2}\right)$ & $26.05 \pm 4.55$ & $27.96 \pm 5.37$ & $<0.05$ \\
FBS $(\mathrm{mg} / \mathrm{dl})$ & $138.47 \pm 45.46$ & $149.02 \pm 52.024$ & 0.24 \\
PPBS (mg/dl) & $195.90 \pm 61.05$ & $200.59 \pm 61.82$ & 0.68 \\
HbA1c (\%) & $9.16 \pm 7.93$ & $8.4 \pm 2.13$ & 0.50 \\
$\begin{array}{l}\text { Serum creatinine } \\
\text { (mg/dl) }\end{array}$ & $0.99 \pm 0.25$ & $0.92 \pm 0.30$ & 0.17 \\
Creatinine clearance & $90.02 \pm 29.69$ & $78.20 \pm 22.61$ & $<0.05$ \\
(ml/minute) & & & \\
Duration of diabetes & $11.31 \pm 7.68$ & $10.64 \pm 6.88$ & 0.62 \\
Systolic BP (mmHg) & $133.33 \pm 16.11$ & $136.85 \pm 18.87$ & 0.13 \\
Diastolic BP (mmHg) & $80.79 \pm 11.08$ & $79.60 \pm 11.09$ & 0.41 \\
\hline
\end{tabular}

All the values expressed as mean \pm SD, Students t test, BMI: Body mass index, FBS: Fasting blood sugar, PPBS: Post-prandial blood sugar, BP: Blood pressure, SD: Standard deviation

$\pm 48.95 \mathrm{mg} / \mathrm{dl}$. In microalbuminuric patients and nonalbuminuric patients FBS was $156.16 \pm 59.56$ and $134.92 \pm 41.24 \mathrm{mg} / \mathrm{dl}$. The relationship between the two groups was significant. The mean PPBS was $198.18 \pm 61.20 \mathrm{mg} / \mathrm{dl}$. In microalbuminuric patients and normoalbuminuric patients PPBS were found to be $226.5 \pm 65.66$ and $187.27 \pm 26.07 \mathrm{mg} / \mathrm{dl}$, it was found to be statistically significant in baseline characteristics but not in the Pearson correlation coefficient.

\section{DISCUSSION}

This prospective study presents data on the prevalence and significance of microalbuminuria with age, duration of diabetes, 
Table 4: Prevalence of microalbuminuria in relation to duration of diabetes

\begin{tabular}{lllll}
\hline $\begin{array}{l}\text { Duration of } \\
\text { diabetes (years) }\end{array}$ & $\begin{array}{l}\text { Number of } \\
\text { microalbuminuric } \\
\text { patients (n=32) }\end{array}$ & $\begin{array}{l}\text { Percentage of } \\
\text { microalbuminuric patients }\end{array}$ & $\begin{array}{l}\text { Number of } \\
\text { normoalbuminuric } \\
\text { patients (n=83) }\end{array}$ & $\begin{array}{l}\text { Percentage of } \\
\text { normoalbuminuric } \\
\text { patients }\end{array}$ \\
\hline $1-5$ & 7 & 21.875 & 21 & 25.301 \\
$6-10$ & 8 & 25 & 21 & 25.301 \\
$11-15$ & 8 & 25 & 13 & 26.506 \\
$15-20$ & 2 & 6.25 & 6 & 15.662 \\
$>20$ & 7 & 21.875 & 15 & 7.228 \\
\hline
\end{tabular}

All the values expressed as number and percentage

HbA1c, blood sugar profile, BP, and renal parameters of Type 2 diabetes patients. In our present study, the overall prevalence of microalbuminuria has shown at $27.82 \%$, which was much higher when compared to the study by Afkhami-Ardekani et al. were prevalent reported at $14.2 \%$ [7]. In the present study, the prevalence of microalbuminuria among males and females were equal percentage $13.91 \%$ and $13.91 \%$, respectively. The prevalence of microalbuminuria was not statistically different from the males and females. The similar study was conducted in India by Varghese et al. reported an increased prevalence of microalbuminuria in Indian men compared with Indian women [9]. In our study, there was statistically significant difference in FBS and postprandial blood sugar in both groups. In our study, the mean $\mathrm{HbA}_{1} \mathrm{c}$ level was significantly higher in males and lower in females. Another one study by Haghighatpanah et al., the mean of HbA1c level was significantly higher in females and lower in males [10]. A study conducted by Acharya et al., reported that their study had a positive correlation of microalbuminuria with duration of diabetes and HbA1c level [11]. Another one similar study conducted by Mandal and Jyothrimayi results insignificant increase in urine microalbumin levels and HbA1c levels in the study group when compared to control group [12]

The present study results in weak positive correlation of degree of albuminuria with age. Previous studies have also shown positive correlation of microalbuminuria with the age of Type 2 diabetes patients [13,14]. A similar study conducted by Varghese et al. reported that there was statistical correlation was found between microalbuminuria and age [9]. Our study has shown significant differences between both groups in baseline characteristics of BMI and but the correlation between microalbuminuria and BMI was not seen.

Creatinine clearance has shown a weak negative correlation with microalbuminuria in our study and statistically significant, indicating impaired kidney function. Similar studies have also shown negative correlation with microalbuminuria [15-17]. Gender-wise significance has seen in creatinine clearance. Our present study has shown a positive correlation of microalbuminuria with duration of diabetes which was in accordance with many previous reports. Another one study conducted by Shastry et al., reported that $95 \%$ of elderly diabetes and $50 \%$ of younger diabetes had impaired creatinine clearance [18].

The present study has shown the moderate positive correlation of systolic BP was seen. A similar study carried out by Debbarma et al. reported the microalbuminuric patients had significantly increased systolic and diastolic BP compared to normoalbuminuric subjects. Plasma glucose, especially postprandial glucose level and HbA1c level were significantly higher in microalbuminuric group compared with the normoalbuminuric group [19].

\section{CONCLUSION}

The prevalence of microalbuminuria in this study was $27.82 \%$ in Type $2 \mathrm{DM}$, which is the predictor of later development of diabetic nephropathy. Incidence of microalbuminria increases with age, duration of diabetes, blood sugar levels, and hypertension. There is no association of BMI and sex on the prevalence of microalbuminuria in Type 2 DM. Creatinine clearance has shown a weak negative correlation with microalbuminuria in our study and statistically significant indicating impaired kidney function. American diabetes association recommends that patients with Type 2 diabetes be tested for albuminuria at the time of initial diabetes diagnosis and yearly thereafter.

\section{Study limitations}

This study had a relatively small sample size. Larger sample size must be considered in the future investigate the associations observed in the present study. However, it can serve as the pilot study for such investigations.

\section{ACKNOWLEDGMENTS}

The authors would like to thank Aruna Diabetes Center, Choolaimedu, Chennai.

\section{REFERENCES}

1. Dabla PK. Renal function in diabetic nephropathy. World J Diabetes 2010;1(2):48-56

2. Gregg EW, Li Y, Wang J, Burrows NR, Ali MK, Rolka D, et al. Changes in diabetes-related complications in the United States, 1990-2010. N Engl J Med 2014;370(16):1514-23.

3. Basi S, Fesler P, Mimran A, Lewis JB. Microalbuminuria in Type 2 diabetes and hypertension: A marker, treatment target, or innocent bystander? Diabetes Care 2008;31 Suppl 2:S194-201.

4. Lucy E, Ide Y, Akani NA. Microalbuminuria: It's significance, risk factors and methods of detection. Niger Health J 2011;11(1):1-7.

5. Wrone EM, Carnethon MR, Panaliappan LP, Formann SP. Association of dietary protein intake and microalbuminuria in healthy adults: Third national health and nutrition examination survey. Am J Kidney Dis 2003;41:580-7.

6. Knight EL, Kramer HM, Curhan GC. High-normal blood pressure and microalbuminuria. Am J Kidney Dis 2003;41(3):588-95.

7. Afkhami-Ardekani M, Modarresi M, Amirchaghmaghi E. Prevalence of microalbuminuria and its risk factors in Type 2 diabetic patients. Indian J Nephrol 2008;18(3):112-7.

8. Mogensen CE. Preventing end-stage renal disease. Diabet Med 1998;15 Suppl 4:S51-6.

9. Varghese A, Deepa R, Rema M, Mohan V. Prevalence of microalbuminuria in Type 2 diabetes mellitus at a diabetes centre in southern India. Postgrad Med J 2001;77(908):399-402.

10. Haghighatpanah M, Tunga G, Khare S, Mallayasammy S. Correlation of glycosylated hemoglobin levels with fasting and postprandial glucose in South Indian Type 2 diabetic patients. Int J Pharm Pharm Sci 2016;8(8):285-8.

11. Acharya K, Regmi S, Sapkota AS, Raut M, Jha B. Microalbumin status in relation to glycated heamoglobin and duration of Type 2 diabetes mellitus. Ann Clin Chem Lab Med 2015;1(1):21-4.

12. Mandal GK, Jyothrimayi D. Comparative study of microalbuminuria and glycated haemoglobin levels in Type 2 diabetic complications. Asian J Pharm Clin Res 2016;9(2):356-60.

13. Ruilope LM, Segura J. Predictors of the evolution of microalbuminuria. Hypertension 2006;48(5):832-3.

14. Metcalf P, Baker J, Scott A, Wild C, Scragg R, Dryson E. Albuminuria in people at least 40 years old: Effect of obesity, hypertension, and hyperlipidemia. Clin Chem 1992;38(9):1802-8.

15. Chowta NK, Pant P, Chowta MN. Microalbuminuria in diabetes mellitus: Association with age, sex, weight, and creatinine clearance. 
Indian J Nephrol 2009;19(2):53-6.

16. Dinneen SF, Gerstein HC. The association of microalbuminuria and mortality in non-insulin-dependent diabetes mellitus. A systematic overview of the literature. Arch Intern Med 1997;157(13):1413-8.

17. Baghel M, Modala S, Kumar BJ, Parimala P. Correlation of creatinine clearance and urine microalbumin in Type 2 diabetes mellitus. Int $\mathrm{J}$
Basic Appl Med Sci 2014;4(2):182-6.

18. Shastry R, Adhikari MR, Kotian MS. Is renal impairment concealed in elderly diabetes? Int J Pharm Pharm Sci 2016;8(12):163-6.

19. Debbarma B, Debbarma R, Pegu AK. Significance of microalbuminuria in newly diagnosed Type 2 diabetes mellitus. IOSR J Dent Med Sci $2015 ; 14(8): 40-7$ 